\title{
KINETICS OF PEARLITE SPHEROIDIZATION
}

\begin{abstract}
The pearlite spheroidization in $\mathrm{Fe}-0.76 \% \mathrm{C}$ high purity steel was investigated. The samples of a coarse pearlite microstructure were isothermal annealed at $700,680,660,640$ and $620^{\circ} \mathrm{C}$ for various times, up to 800 hours. For quantitative description of the spheroidization process stereological parameter, $S_{V}$ (ferrite/cementite interface surface density) was used. The activation energy $104.8 \pm 11.4 \mathrm{~kJ} / \mathrm{mol}$ was found for the spheroidization process. This value shows good agreement with the activation energy for iron and carbon diffusion along a ferrite/cementite interface, so the coupled interface diffusion is the rule-controlling process.

Keywords: pearlite spheroidization, sterology, activation energy
\end{abstract}

\section{Introduction}

The process of pearlite spheroidization consists in a change of the shape of the cementite plates into the shape which is approximately spherical, with the preservation of the constant phase volume, while is can be accompanied by diffusion growth [1] The first stage of the process is fragmentation, i.e. division of the plates into smaller ones. Next, gradual rounding of the plates it observed, until a semi-spherical shape is obtained. In the further stages, coagulation of the spheroidized particles may occur [2]. The complexity of the processes taking place during spheroidization has its source in the substructure of ferrite and cementite, the geometrical characteristics of the phases (deviations from the plate morphology), the properties of the interface boundaries, etc.

There is no specific, unquestioned concept of both the mechanism and kinetics of pearlite spheroidization. The proposed interpretations are incomplete in character, often referring only to certain, selected aspects of the process and they are not sufficiently verified experimentally [3-10]. In this context, this problematics is still interesting, both from the theoretical and the experimental point of view. This work concerns the kinetics of pearlite spheroidization and it constitutes a continuation of the research performed and published earlier [11]. Its aim is to determine and interpret the activation energy of the spheroidization process.

\section{Experimental}

The material for the test was a model alloy $\mathrm{Fe}-\mathrm{C}$ with the carbon content of $0.76 \%$ (Tab. 1). In order to obtain the microstructure of coarse pearlite, thermal treatment was conducted: (1) austenitization $900^{\circ} \mathrm{C} / 0.5 \mathrm{~h},(2)$ isothermal annealing (lead bath) $700^{\circ} \mathrm{C} / 3.5 \mathrm{~h}$.

The spheroidizing (isothermal) annealing of the samples of a coarse pearlite microstructure was performed at 5 temperatures: $700,680,660,640$ and $620^{\circ} \mathrm{C}$, in the time range from 5 to 800 hours. Pearlite microstructures for temperatures 700 and $620^{\circ} \mathrm{C}$ after different annealing times are presented in Fig. 1 and Fig. 2.

TABLE 1

Chemical composition of experimental material

\begin{tabular}{|c|c|c|c|c|c|c|c|c|c|c|}
\hline \hline \multicolumn{10}{|c|}{ Chemical composition, \% weight } \\
\hline C & Mn & Si & P & S & Cr & Ni & $\mathbf{C u}$ & Al & $\mathbf{N}$ & Fe \\
\hline 0.76 & 0.05 & 0.01 & 0.002 & 0.012 & 0.03 & 0.03 & 0.01 & 0.01 & 0.009 & balance \\
\hline
\end{tabular}

\section{Quantitative microstructure evaluation}

With the purpose of a quantitative presentation of the spheroidization process, parameter $S_{V}$ was used - the relative surface of the ferrite/cementite interface boundaries. The measurements were performed by the random secant method [12]. The results of the microstructure measurement are presented in Table 2. Figure 3 shows values of $S_{V}$ for different annealing temperatures in function of time.

\footnotetext{
AGH UNIVERSITY OF SCIENCE AND TECHNOLOGY, FACULTY OF METALS ENGINEERING AND INDUSTRIAL COMPUTER SCIENCE, 30 MICKIEWICZA AV., $30-059$ KRAKÓW, POLAND

Corresponding author: matus@agh.edu.pl
} 

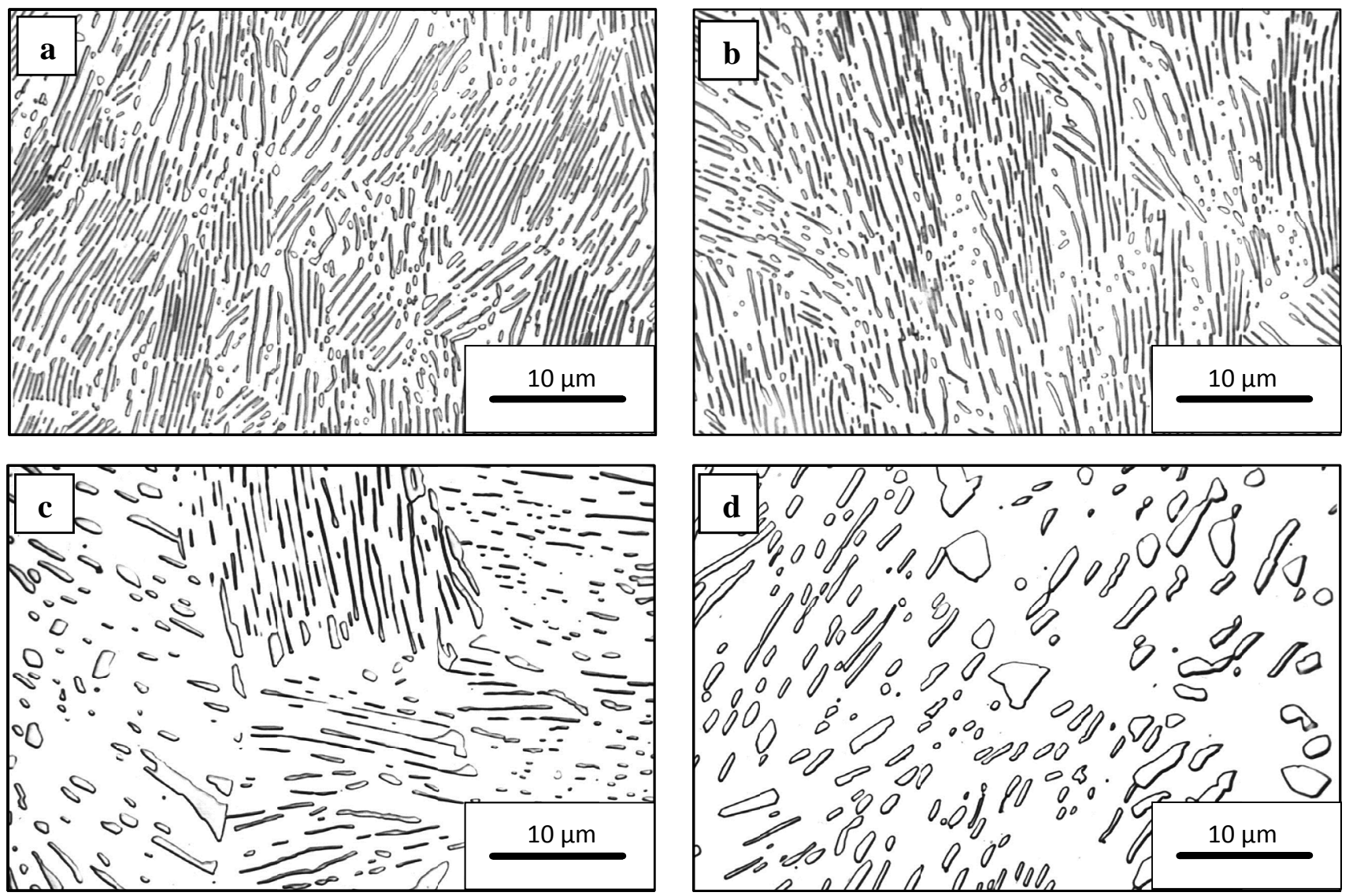

Fig. 1. Pearlite microstructure at $700^{\circ} \mathrm{C}$ at initial stage (a) and after different annealing times: $10 \mathrm{~h}(\mathrm{~b}), 100 \mathrm{~h}$ (c) and $800 \mathrm{~h}$ (d), (Etched $2 \%$ picral)
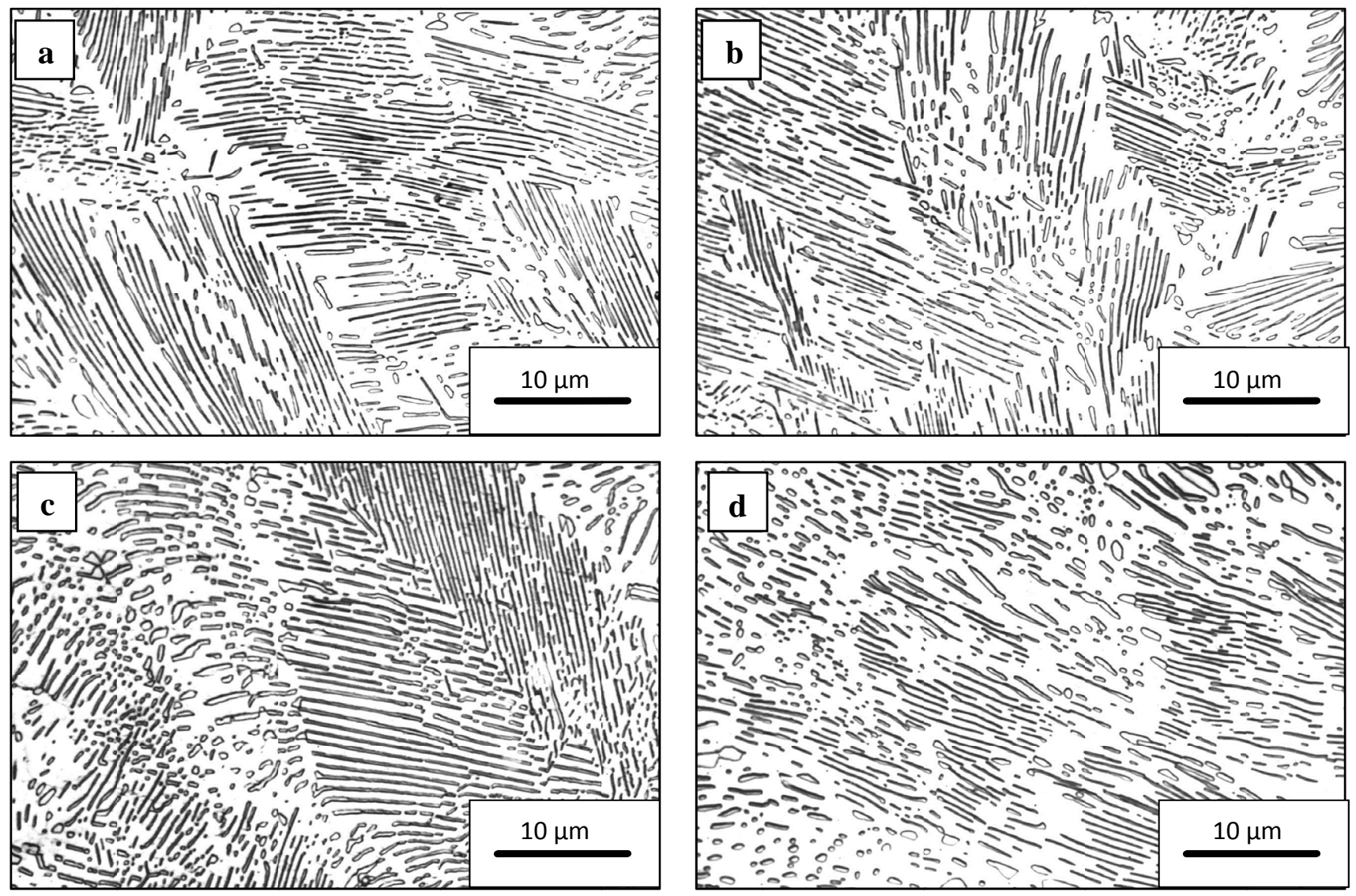

Fig. 2. Pearlite microstructure after different annealing times at $620^{\circ} \mathrm{C}$. Etched $2 \%$ picral, a) 50 ; b) 100 ; c) 400 ; d) 800 hours 
TABLE 2

The results of $S_{V}$ measurements

\begin{tabular}{|c|c|c|c|c|c|c|c|c|c|c|}
\hline & \multicolumn{10}{|c|}{ Annealing time, $h$} \\
\hline & $\begin{array}{c}\text { Initial } \\
\text { microstructure }\end{array}$ & 5 & 10 & 20 & 50 & 100 & 200 & 400 & 600 & 800 \\
\hline Temp, ${ }^{\circ} \mathrm{C}$ & \multicolumn{10}{|c|}{$S_{V}, \mathbf{m m}^{-1}$} \\
\hline 700 & \multirow{5}{*}{$\begin{array}{c}2031.8 \\
\pm 57.4\end{array}$} & $\begin{array}{c}1784.3 \\
\pm 62.2\end{array}$ & $\begin{array}{l}1623.6 \\
\pm 47.3\end{array}$ & $\begin{array}{l}1490.0 \\
\pm 45.7\end{array}$ & $\begin{array}{l}1239.7 \\
\pm 40.6\end{array}$ & $\begin{array}{c}1079.5 \\
\pm 33.6\end{array}$ & $\begin{array}{l}851.4 \\
\pm 33.4\end{array}$ & $\begin{array}{l}677.9 \\
\pm 24.7\end{array}$ & $\begin{array}{l}580.7 \\
\pm 22.0\end{array}$ & $\begin{array}{c}522.2 \\
\pm 19.92\end{array}$ \\
\hline 680 & & - & $\begin{array}{l}1748.7 \\
\pm 52.9 \\
\end{array}$ & - & $\begin{array}{l}1443.9 \\
\pm 42.3 \\
\end{array}$ & $\begin{array}{l}1278.7 \\
\pm 40.6 \\
\end{array}$ & $\begin{array}{c}1077.1 \\
\pm 37.1 \\
\end{array}$ & $\begin{array}{l}923.3 \\
\pm 31.6 \\
\end{array}$ & $\begin{array}{l}801.4 \\
\pm 28.1 \\
\end{array}$ & $\begin{array}{r}709.0 \\
\pm 23.4 \\
\end{array}$ \\
\hline 660 & & - & - & - & $\begin{array}{l}1601.8 \\
\pm 55.1\end{array}$ & $\begin{array}{c}1477.3 \\
\pm 50.4\end{array}$ & $\begin{array}{c}1302.0 \\
\pm 41.0 \\
\end{array}$ & $\begin{array}{l}1107.4 \\
\pm 33.7\end{array}$ & $\begin{array}{l}1005.4 \\
\pm 32.8\end{array}$ & $\begin{array}{l}946.0 \\
\pm 31.7 \\
\end{array}$ \\
\hline 640 & & - & $\begin{array}{c}1871.0 \\
\pm 57.5 \\
\end{array}$ & - & $\begin{array}{c}1764.5 \\
\pm 52.7 \\
\end{array}$ & $\begin{array}{c}1609.6 \\
\pm 45.6 \\
\end{array}$ & - & $\begin{array}{l}1336.8 \\
\pm 44.7 \\
\end{array}$ & $\begin{array}{l}1238.9 \\
\pm 42.5\end{array}$ & $\begin{array}{l}1169.0 \\
\pm 38.0 \\
\end{array}$ \\
\hline 620 & & - & $\begin{array}{l}1929.4 \\
\pm 59.7\end{array}$ & - & $\begin{array}{l}1798.0 \\
\pm 57.9\end{array}$ & $\begin{array}{l}1723.8 \\
\pm 58.5\end{array}$ & - & $\begin{array}{l}1504.0 \\
\pm 46.2\end{array}$ & $\begin{array}{l}1454.0 \\
\pm 49.3 \\
\end{array}$ & $\begin{array}{l}1400.8 \\
\pm 46.3\end{array}$ \\
\hline
\end{tabular}

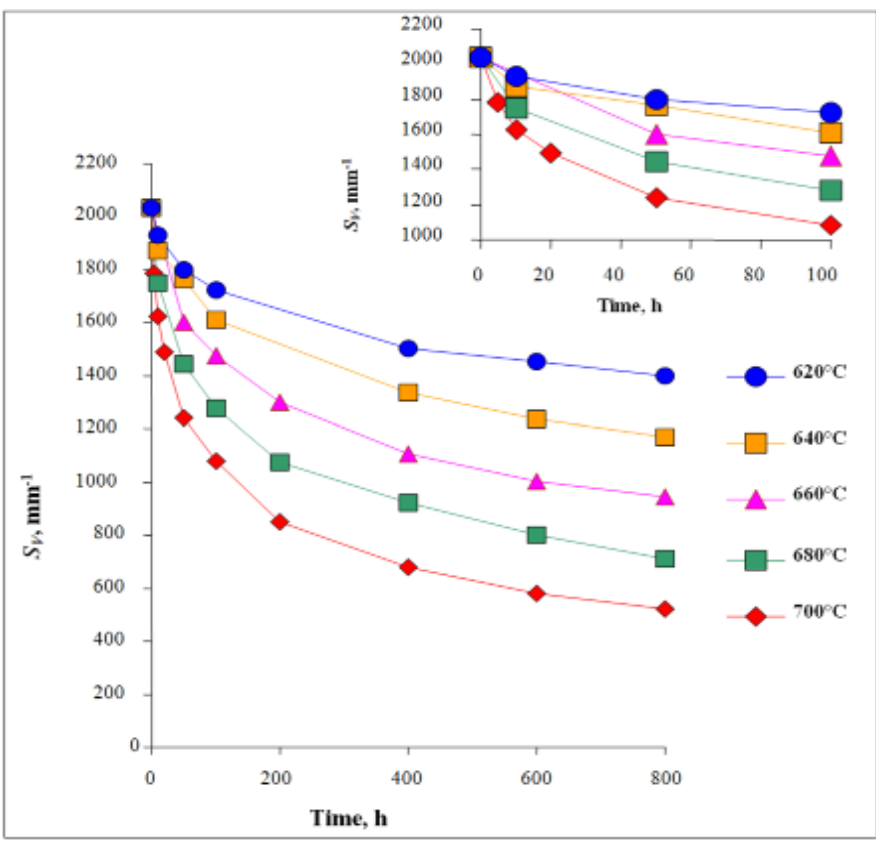

Fig. 3. Changes of the surface density $S_{V}$ of the ferrite/cementite interface boundaries depending on time and temperature

\section{Estimation of kinetic equations and activation energy}

In the description of the kinetics of the spheroidization process, the Avrami equation was applied [13] in the form proposed by Nijhof $[3,4,6]$ :

$$
\alpha=1-\exp \left(-k t^{n}\right)
$$

where: $\alpha$ - degree of spheroidization

$$
\alpha=\left[S_{V}(t=0)-S_{V}(t)\right] /\left[S_{V}(t=0)-S_{v}(t=\infty)\right]
$$

$S_{V}(t=0)$ - initial value of $S_{V}$ corresponding to the initial state,

$S_{V}(t)$ - value of $S_{V}$ after annealing time $t$,

$S_{V}(t=\infty)$ - final value of $S_{V}$; assumed: $S_{V}=500, \mathrm{~mm}^{-1}$,

$k, n$ - equation parameters.
There is no clear, physical interpretation of the Avrami constants $k$ and $n$. Under certain conditions, the constant $k$ can be considered as the rate constant of the process, whereas the constant $n$ can be considered as dependent on the diffusion mechanism.

The parameters $n$ and $k$ of Eq. (1) were determined by the least square method. The results of the approximation are presented in Fig. 4 and Table 3; the linearity in the logarithmic coordinates means correctness of the approximation (the equation is satisfied by the experimental data) as well as the isokineticity of spheroidization. In reference to annealing at $700^{\circ} \mathrm{C}$, the Avrami Eq. (1) was determined considering the time range from 5 to 200 hours (after times above 200 hours, it seems that coagulation is the dominating process).

TABLE 3

The results of approximation for $n$ and $k$ parameters

\begin{tabular}{|c|c|c|c|c|c|}
\hline \hline Temp $^{\circ}{ }^{\circ} \mathbf{C}$ & $\mathbf{7 0 0}$ & $\mathbf{6 8 0}$ & $\mathbf{6 6 0}$ & $\mathbf{6 4 0}$ & $\mathbf{6 2 0}$ \\
\hline$n$ & 0.5535 & 0.5075 & 0.4871 & 0.4734 & 0.4615 \\
\hline$k$ & 0.0798 & 0.0647 & 0.0487 & 0.0348 & 0.0256 \\
\hline
\end{tabular}

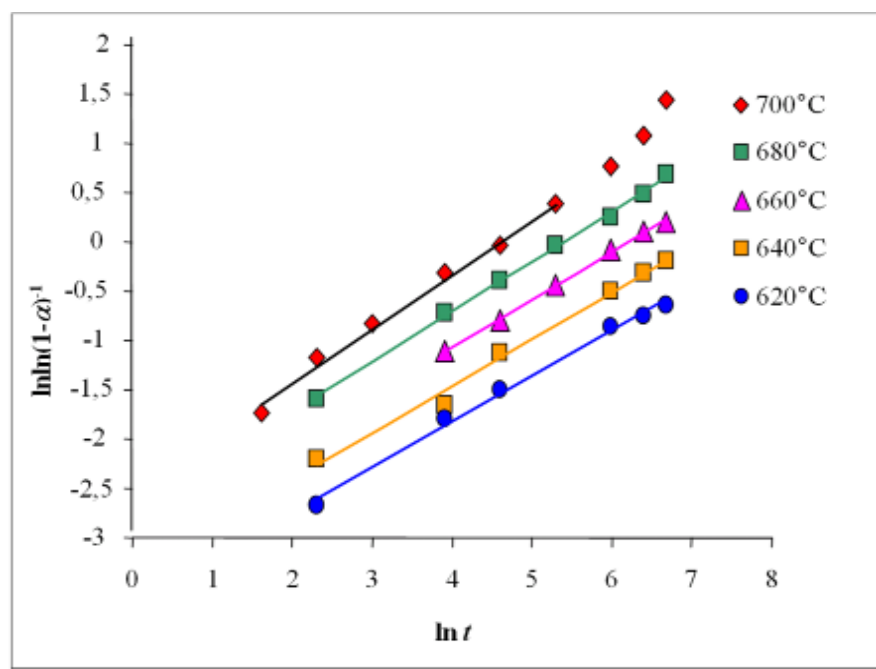

Fig. 4. Dependence of the degree of spheroidization $\alpha$ on time $t$ in logarithmic coordinates (experimental data and its approximation by the Avrami equation) 
The activation energy was determined based on the Arrhenius equation [13],

$$
k=A \times \exp ((-Q) /(R \times T))
$$

where the parameter $k$ from Eq. (1) was assumed as the rate constant. The results are given in Table 4 and Fig. 5.

where:

$k$ - rate constant,

$A$ - pre-exponentional factor,

$Q-$ activation energy,

$R$ - Boltzman constant,

$T$ - temperature, $\mathrm{K}$.

TABLE 4

Estimated activation energy of pearlite spheroidization

\begin{tabular}{|c|c|c|}
\hline \hline \multirow{2}{*}{ Temperature, $^{\circ} \mathbf{C}$} & \multicolumn{2}{|c|}{ Activation energy, $\boldsymbol{Q}$} \\
\cline { 2 - 3 } & $\mathbf{k J} / \mathbf{m o l}$ & $\mathbf{k c a l} / \mathbf{m o l}$ \\
\hline $700 ; 680 ; 660 ; 640 ; 620$ & $104.8 \pm 11.4$ & $25.1 \pm 2.73$ \\
\hline
\end{tabular}

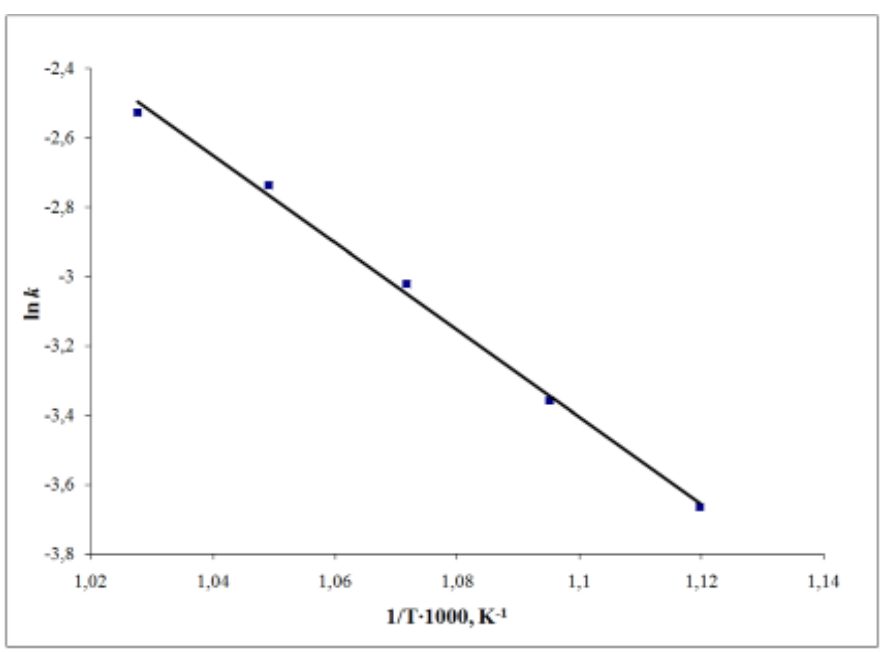

Fig. 5. Graphical presentation of determining the activation energy, $Q$ based on (Eq. 2)

\section{Discussion of results, conclusions}

The investigations of pearlite spheroidization was conducted on coarse pearlite microstructure $\left(S_{V}=2031.8 \mathrm{~mm}^{-1}\right)$. Progress of spheroidization process is inhomogeneous. Even after long annealing times investigated microstructures consist of cementite particles, well-preserved lamellar colonies and individual plates of cementite.

The quantitative description of microstructure changes was carried out based on the measurement of $S_{V}$ (ferrite/cementite interface surface density). Estimation of parameter $S_{V}$ requires no assumptions about the geometrical properties of measured surface. Relative error of the assessment parameter $S_{V}$ was less than 3.9\%.

Changes of the parameter $S_{V}$ during annealing are shown in (Fig. 3). The nature of the $S_{V}$ changes is independent from annealing temperature. The rate of spheroidization process determines the temperature; the higher annealing temperature the progress of the process, expressing in intensity changes of parameter $S_{V}$ over time, is greater.

To describe changes of the parameter $S_{V}$ during annealing at a given temperature the Avrami Eq. (1) was used. This equation is the most frequently used in the analysis of kinetics experimental data of diffusion phase transformation. One can say that the nature of the parameter $S_{V}$ changes as a function of temperature is Avrami type (Fig. 4), of course, for a given temperature. Parameter $k$ in Eq. (1) can be considered as a constant rate of spheroidization process. Therefore, the activation energy $Q$ can be determined from the temperature dependence of the constant $k$ using the Arrhenius Eq. (2).

To summarize it can be stated that the test results, especially the agreement with the Avrami Eq. (1), show that the spheroidization process proceeds approximately isokinetically, which makes it possible to determine the activation energy of the process.

The pearlite spheroidization in $\mathrm{Fe}-0.76 \% \mathrm{C}$ high purity steel was investigated. The empirically estimated activation energy assumes the value of $104,8 \mathrm{~kJ} / \mathrm{mol}$ and it is comparable with the one obtained by Nijhof $[3,4,6](Q=126 \mathrm{~kJ} / \mathrm{mol})$ as well as Gogia and Gokhale [9] $(Q=113 \mathrm{~kJ} / \mathrm{mol})$. And so, one should presume that the rate of pearlite spheroidization is determined by the coupled diffusion of $\mathrm{Fe}$ and $\mathrm{C}$ at the ferrite/cementite boundary.

\section{Acknowledgements}

The work has been implemented within the framework of statutory research of AGH University of Science and Technology, contract No 11.11.110. 299 AGH

\section{REFERENCES}

[1] J. Ryś, K. Wiencek, Coagulation phases in alloys, Publishing Śląsk, Katowice, (1970) (in Polish).

[2] P. Matusiewicz, K. Wiencek, Arch. Metall. Mater. 55 (1), 231-238 (2010).

[3] G.H. Nijhof, Accelerated Spheroidization of Cold Rolled Eutektoid Steel, Ph.D. Dissertation, Delftse Universitaire Pers, (1981).

[4] G.H. Nijhof, Härterei Techn. Mitt. 35, 59 (1980).

[5] Y.L. Tian, R.W. Kraft, Metall. Trans. A 18A, 1403 (1987).

[6] G.H. Nijhof, Härterei Techn. Mitt. 36, 242 (1981).

[7] R.W. Kraft, Y.L. Tian, Metall. Trans. A. 18A, 1359 (1987).

[8] M.J. Harrigan, O.D. Sherby, Mat. Sc. and Eng. 7, 177 (1971).

[9] A.K. Gogia, A.M. Gokhale, Metall. Trans. A. 11A, 1077 (1980).

[10] T. Skowronek, W. Ratuszek, K. Chruściel, A. Czarski, K. Satora, K. Wiencek. Arch. Metall. Mater. 49 (4), 961-971 (2004).

[11] A. Czarski, K. Satora, J. Ryś, Materials Engineering, 73-74, 33, (1993).

[12] E.E. Underwood, Quantitative Stereology, Addison-Weseley Publishing Company, (1970).

[14] J.W. Christian, Transformation in Metals and Alloys, Pergamon Press, (1975). 